\title{
Competitive Advantages of the Bulgarian Wine Sector
}

\author{
Gergana Dimitrova ${ }^{1 *}$ \\ ${ }^{1}$ Univerity of Plovdiv 'Paisii Hilendarski', Faculty of Economics and Social Science, 4000 Plovdiv, \\ Bulgaria
}

\begin{abstract}
The wine industry is traditional sector in the Bulgarian economy. However, at the end of the XX century it faced various challenges. Later, it has started to restore and has developed in number of areas. Nowadays it has new characteristics, based on its strengths and weaknesses. Thus, the purpose of the current study is to identify the competitive advantages of the wine sector in Bulgaria. The object of the research are Bulgarian wine producers, who are small and middle size enterprises (SMEs). The focus of the study is a selection of indicators, which contribute for the identification of their competitive advantages. The data used is of own survey, performed among Bulgarian wine producers. The results show that the main advantages are targeted at qualitative wines from authentic local sorts. This justifies the obligatory direction for differentiation and validation of the Bulgarian wine producers by promoting the wines of local varieties and establishing the identity of the wine regions.
\end{abstract}

\section{Introduction}

In a highly competitive environment, in order to increase the competitiveness of the wine industry enterprises, it is necessary to look for opportunities for developing their competitive advantages (their leading strengths), overcoming their weaknesses and developing their competitive potential.

The National Strategy for the Development of Vine and Wine Production in the Republic of Bulgaria 2005-2025 identifies the strengths and the weaknesses of the sector alongside with the opportunities for its development [1]. The winemaking industry is rather significant for the Bulgarian economy as it is a sector with traditions and potential for growth.

Thus, the purpose of the current study is to identify the competitive advantages of the wine sector in Bulgaria. The object of the research are Bulgarian wine producers, who are small and middle size enterprises. The focus of the study is a selection of indicators, which contribute for the identification of the competitive advantages of a company.

In our work, we used the following methods and approaches: processing of quantitative data, content analysis, and comparative analysis and the statistic methods: descriptive analysis and factor analysis.

* Corresponding author: gergana_dim@uni-plovdiv.bg 
Our sources of data were Executive Agency on Vine and Wine (EAVW) in Bulgaria, Ministry of Agriculture, Food and Forestry of Bulgaria, National Vine and Wine Chamber and information from own empirical research.

Our own quantitative data was obtained by online survey conducted in the period December 2019 - January 2020 through structured interviews using own questionnaire. The collected data was processed with IBM SPSS Statistics.

The article is structured as follows:

1) The first part after the introduction consist of literature review on the conceptual remarks, regarding the factors of competitiveness. Furthermore, it includes a review of the situation in the Bulgarian industry and a SWOT analysis of the sector. The first part is a base for the empirical data, presented in the Results and Discussion section;

2) The next part presents the methods used in the study;

3) The third part, named „Results and Discussion“ introduce some results of our own survey among SMEs wine producers, which results are relevant to the competitive advantages;

4) In the concluding part makes a summary of the results and recommendations for future research in the field of competitiveness of wine industry in Bulgaria.

\section{Literature Review}

\subsection{Factors of Competitiveness}

The wine market (national and international) is characterized by growing competition. It results from the influence of multiple factors of a great turbulent environment where the world wine sector functions. Among these factors which affect the growing level of competition in the wine sector, the following may be highlighted [2]

1) New competitors emerge. The Old continent, characterized by established wine production traditions, which, until a few years ago, formed the appearance of world wine and set trends, now has to deal with competing countries from the so-called "New wine world" Chile, Argentina, Australia, the USA, etc. The last rely on more modern and contemporary approach in wine production and become more serious about leading the world wine market.

2) Climate changes which inevitably affect the quality and quantity of the wine production;

3) Change in clients' preferences in a response to which there is a necessity of satisfying customers' requirements in different tastes, preferences, purchasing power, wine culture and others. All these factors reflect over offering a huge variety of wine and trademarks.

The need for strategic differentiation, greatly related to increasing the Bulgarian wine producers' innovation activity, is evident $[3,4]$. A possible direction for their competitive positioning in a highly competitive environment would be to highlight them through their leading strengths (competitive advantages) and overcoming the major weaknesses of the sector.

Establishing image - recognizable, popular and imposed image among the customers is a leading tool for influencing and forming decisions for the purchase and usage of a given product/service [8].

The role of consumer connectivity is also indisputable and is related to the creation of brand-loyal customers. It is a leading aim for every business [9:37, 39] and a prerequisite in the present postmodern society which is consumer-orientated [10:15].

\subsection{Bulgarian Wine Industry: SWOT analysis}

In 2005, the Ministry of Agriculture, Food and Forestry of Bulgaria and the National Vine and Wine Chamber developed the National Strategy for the Development of Vine and Wine 
Production in the Republic of Bulgaria 2005-2025 which presents the strengths and weaknesses of the Bulgarian wine production. The strategy aims to reveal the opportunities and to point out the way for the development of the sector regarding the wine production and markets for its realization. It identifies as the strong points of the sector the following: available capacity for quality wines; qualified experts; good varietal structure of vineyards; national chauvinism, regarding the consumption of local wines; developed tourism, increasing number of foreign tourists; imposed goodwill on the country as a wine producer. [1]

However, numerous weaknesses of the sector are also identified and they include physically and morally outdated technologies and equipment; outdated training and research programs; failure to comply with good manufacturing practice; lack of market orientation in the style of wine; insufficient consumer protection and unfair competition; unorganized wine production at home; lack of national budget for promotion of the wine sector; lack of developed marketing and distribution system; underdeveloped culture of wine consumption; few exporting wineries; a large number of quality wines of controlled and guaranteed origin as evidence of a lack of origin culture; high consumption of alcoholic beverages. [1]

Our traditional local wine sorts are among the evident competitive advantages of local wine production. This gave the reason in 2005 to highlight the qualitative wines (with PGI and PDO) as a key competitive advantage of the Bulgarian wine production.

For the period of introducing the Strategy up to now many types of researches have been done regarding exploring the wine industry. Their results (part of which are shown below) to some extent overlap with the conclusions from 2005 . However, some novelty is also identified.

In 2012 was conducted and presented a SWOT analysis of the wine industry. Its results demonstrated that part of the sector weaknesses were still unsolved. Among them are those related to the selling of the Bulgarian wines. [5]

But according to the data from 2015 research [6] the main weakness of the sector was namely the lack of adequate marketing strategy for their realization. It shows that 10 years later there are still serious difficulties regarding the establishing qualitative wines from authentic local sorts at the world markets.

A more recent study of Dimitrova shows some transformation in the strengths and weaknesses of the sector and alongside demonstrates the opportunities and threats for the future development. Her research in 2019 highlighted difficulties in a relation to their production as a result of a difficult procedure for their certification. (Table 1). [2]

Table 1. SWOT analysis of the Bulgarian Wine Sector, 2019

\begin{tabular}{|c|c|}
\hline Strengths & Weaknesses \\
\hline $\begin{array}{l}\checkmark \quad \text { Experience and traditions in vine and wine; } \\
\checkmark \text { Wide range of wines; } \\
\checkmark \text { Quality of Bulgarian wines; } \\
\checkmark \text { Traditions in wine export; } \\
\checkmark \text { Qualified specialists in viticulture and wine } \\
\text { production; } \\
\checkmark \quad \text { Variety of wine varieties; } \\
\checkmark \text { Growing wine culture among wine consumers; } \\
\checkmark \text { Innovations and modern technologies in } \\
\text { winemaking; } \\
\checkmark \text { Wine tourism. }\end{array}$ & $\begin{array}{l}\checkmark \quad \text { Low share of quality wine production (with } \\
\text { PDO and PGI); } \\
\checkmark \quad \text { Low levels and instability of sectoral } \\
\text { integration processes; } \\
\checkmark \quad \text { Shortage of financial resources; } \\
\checkmark \quad \text { Insufficient advertising; } \\
\checkmark \quad \text { Lack of culture for lasting cooperation } \\
\text { between winemakers; } \\
\checkmark \quad \text { Low labor productivity; } \\
\checkmark \quad \text { High production costs; } \\
\checkmark \quad \text { The image (popularity) of Bulgarian wine } \\
\text { has not been imposed on world markets; } \\
\checkmark \quad \text { Shortage of raw materials of constant } \\
\text { quantity and quality. }\end{array}$ \\
\hline Opportuni & Threats \\
\hline $\begin{array}{l}\checkmark \quad \text { Or } \\
\text { promo }\end{array}$ & $\begin{array}{ll}\checkmark & \text { In }\end{array}$ \\
\hline
\end{tabular}




\begin{tabular}{|c|c|}
\hline $\begin{array}{l}\checkmark \text { Favorable conditions (terroir) for the } \\
\text { production of regional wines; } \\
\checkmark \quad \text { Perspectives on the enforcement of local } \\
\text { varieties and regional wines (regional identity); } \\
\checkmark \text { Opportunity to expand markets (export) } \\
\checkmark \text { Opportunities for EU funding; } \\
\checkmark \text { Growing interest in wine tourism; } \\
\checkmark \text { Cultural-historical heritage; } \\
\checkmark \quad \text { Existing competitive potential in the } \\
\text { development of the sector; } \\
\checkmark \quad \text { Stable levels of wine consumption in the } \\
\text { country and around the world; } \\
\checkmark \text { Predominant of local wines in Bulgaria. }\end{array}$ & $\begin{array}{l}\checkmark \text { Lack of strategy for the development of } \\
\text { regional wines and the imposition of an } \\
\text { aggregate product; } \\
\checkmark \text { Insufficient government support for SMEs } \\
\text { wine producers; } \\
\checkmark \text { Climate changes, affecting the quality and } \\
\text { the quantity of wine; } \\
\checkmark \text { Insufficient information availability } \\
\text { regarding funding opportunities; } \\
\checkmark \text { Insufficient information about consumer } \\
\text { preferences; } \\
\checkmark \text { Low consumer purchasing power; } \\
\checkmark \text { Presence of unlicensed wine producers; } \\
\checkmark \text { A constant threat of new competitors } \\
\text { entering; } \\
\checkmark \text { Lack of legislative support for SMEs wine } \\
\text { producers }\end{array}$ \\
\hline
\end{tabular}

Source: Dimitrova, G. (2019), [2]

The three leading strength of the Bulgarian wine production as defined by the SMEs wine producers are the wine quality $(90 \%)$, the established traditions in relation to vine growing and wine production $(80 \%)$ and the uniqueness of the offered tourist product (wine through wine tourism) and the cultural and historical heritage (75\%). The three main weaknesses according to them are the lack of government support (75\%), high production costs $(70 \%)$ and the advertisement (65\%). [2]

The main factors, which Bulgarian winemakers regard as significant for forming their competitiveness are access to suppliers (75\%), image of the trademark $(70 \%)$, consumer connectivity (63\%) and production differentiation (54\%). [2]

Part of the measures directed towards overcoming the wine sector weaknesses was stated in the National Program for supporting the vine and wine sector in Bulgaria 2014-2018 and subsequently and the National program for supporting the vine and wine sector in Bulgaria 2019-2023 [7]. These measures are directed towards: restructuring and conversion of the vines; investments in enterprises (later redirected towards the measure "restructuring and conversion of vines"); green harvesting; popularizing markets of third parties. Furthermore, particularly relevant for the current study is the aim, regarding the competition stated as "one of the main government policies in the vine and wine sector in Bulgaria is increasing the wine producers' competitiveness, rebalancing supply and demand at the wine market, preventing market crisis". [7]

\section{Methods}

The empirical results, presented in part Results and Discussion are obtained through a structured interview, conducted in the period December 2019 - January 2020. An evaluation by an expert opinion is executed, as the respondents are the owners, managers or marketing managers of the researched enterprises.

The study was conducted online via 156 online questionnaires were sent by e-mail. 57 of them participated in the survey which represents $37 \%$ response rate and the collected data provides relevant results.

The survey consisted of four sections: general information about the respondent, information about the enterprise, innovations section and competitiveness section.

The competitiveness section consists of ten questions. In the current paper are presented the results for six of them namely. 
In one of the question the respondents were asked to evaluate to what extent each of the suggested factors contributes to the competitiveness of their enterprise. They had to select answer from 1 to 5 as 1 is doesn't contribute at all and 5 is contributes a lot.

In the other five questions the respondents were asked to evaluate various elements of the product, price, distribution, promotion and the management. The respondents were asked to assess to what extent they rely on each of the elements. The assessment had to be made on the scale from 1 to 5 , as 1 is to a very small extent and 5 is to a very high extent. The results, displayed on the figures that follow present the share of answers 4 and 5 for each element.

\section{Results and Discussion}

The results show that all of the Bulgarian wine producers regard the quality of the product as the main strength of the sector. The next significant factor is also related to the product, namely the design and packaging (90\%). Interesting is the fact that the following two factors are associated with the personnel of the enterprise - staff qualification $(89 \%)$ and effective management $(86 \%)$. The financial resources are put on fifth place $(86 \%)$. It is important to notice that the factor that is least regarded as important is the advertising and PR activities. However, still over $50 \%$ of the wine producers believe that it is important (52\%). (Fig. 1)

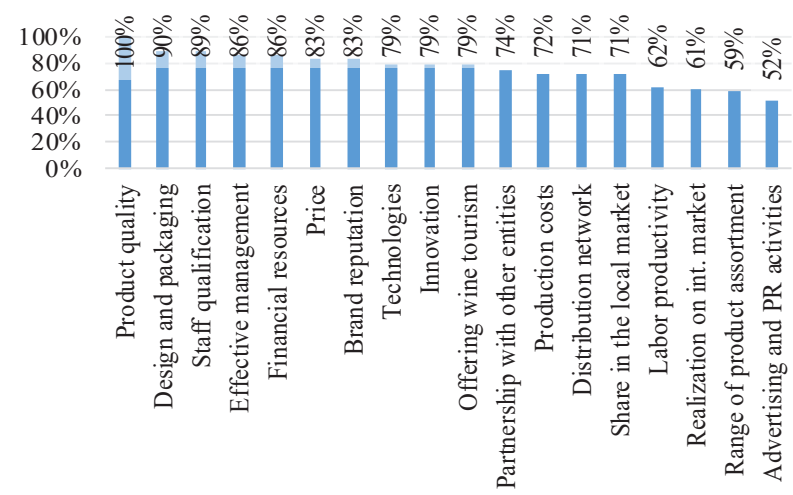

Fig. 1. Competitive advantages of the Bulgarian wine sector, Own data

As the quality of the products is selected as the most important competitive advantage, Fig. 2 displays the ranging of its elements. As much as $96 \%$ of the respondents rely on the quality of the product as competitive advantage, alongside with the trademark (89\%) and its packaging $(86 \%)$. The least selected factor is the product modification as only $59 \%$ of the wine producers rely on it.

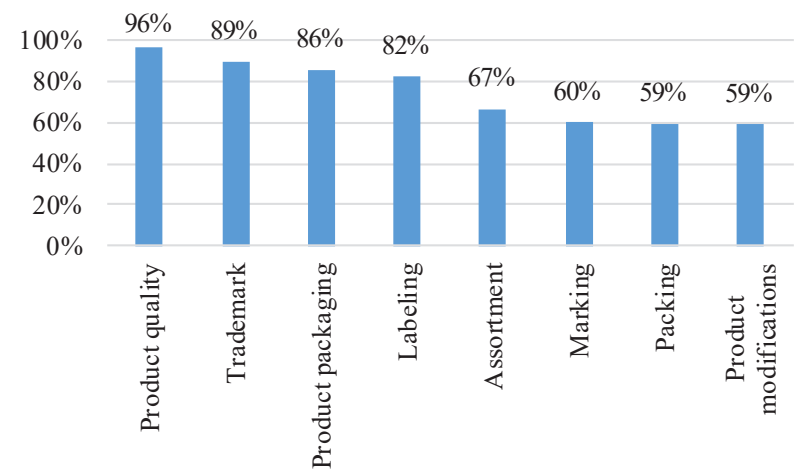


Fig. 2. Reliance of wine producers on product's factors for competitiveness, Own data

Through factor analysis, the factors are grouped according to their importance in the formation of competitive advantages and their role in competitive positioning (Fig. 3).

\section{KMO and Bartlett's Test}

Kaiser-Meyer-Olkin Measure of Sampling Adequacy.

\begin{tabular}{llr}
\hline Bartlett's Test of Sphericity & Approx. Chi-Square &, 783 \\
\cline { 2 - 3 } & df & 120,077 \\
\cline { 2 - 3 } & Sig. &, 000 \\
\hline
\end{tabular}

\section{Total Variance Explained}

\begin{tabular}{|c|c|c|c|c|c|c|c|c|c|}
\hline \multirow[b]{2}{*}{$\begin{array}{l}\text { Comp } \\
\text { onent }\end{array}$} & \multicolumn{3}{|c|}{ Initial Eigenvalues } & \multicolumn{3}{|c|}{$\begin{array}{c}\text { Extraction Sums of Squared } \\
\text { Loadings }\end{array}$} & \multicolumn{3}{|c|}{ Rotation Sums of Squared Loadings } \\
\hline & Total & $\begin{array}{c}\% \text { of } \\
\text { Varianc } \\
\mathrm{e}\end{array}$ & $\begin{array}{r}\text { Cumul } \\
\text { ative \% }\end{array}$ & Total & $\begin{array}{l}\% \text { of } \\
\text { Varian } \\
\text { ce }\end{array}$ & $\begin{array}{c}\text { Cumulative } \\
\%\end{array}$ & Total & $\begin{array}{c}\% \text { of } \\
\text { Variance }\end{array}$ & $\begin{array}{c}\text { Cumulative } \\
\%\end{array}$ \\
\hline 1 & 4,372 & 54,644 & 54,644 & 4,372 & 54,644 & 54,644 & 3,630 & 45,379 & 45,379 \\
\hline 2 & 1,231 & 15,383 & 70,027 & 1,231 & 15,383 & 70,027 & 1,972 & 24,648 & 70,027 \\
\hline 3 & ,763 & 9,536 & 79,563 & & & & & & \\
\hline 4 &, 622 & 7,777 & 87,340 & & & & & & \\
\hline 5 &, 566 & 7,074 & 94,414 & & & & & & \\
\hline 6 &, 232 & 2,901 & 97,314 & & & & & & \\
\hline 7 &, 162 & 2,029 & 99,344 & & & & & & \\
\hline 8 &, 053 & 656 & $\begin{array}{r}100,00 \\
0\end{array}$ & & & & & & \\
\hline
\end{tabular}

Extraction Method: Principal Component Analysis.

\section{Rotated Component Matrix ${ }^{\mathrm{a}}$}

\begin{tabular}{lr|r} 
& \multicolumn{2}{c}{ Component } \\
& 1 & 2 \\
\hline Package &, 891 & \\
\hline Marking &, 868 & \\
\hline Labeling &, 722 &, 587 \\
\hline Assortment &, 707 & \\
\hline Product Packaging (bottle, cap) &, 657 &, 652 \\
\hline Product modification &, 636 & \\
\hline Product Quality (taste, aroma, color ...) & &, 867 \\
\hline Trade mark &, 448 &, 588 \\
\hline
\end{tabular}

Extraction Method: Principal Component Analysis.

Rotation Method: Varimax with Kaiser Normalization.

a) Rotation converged in 3 iterations. 


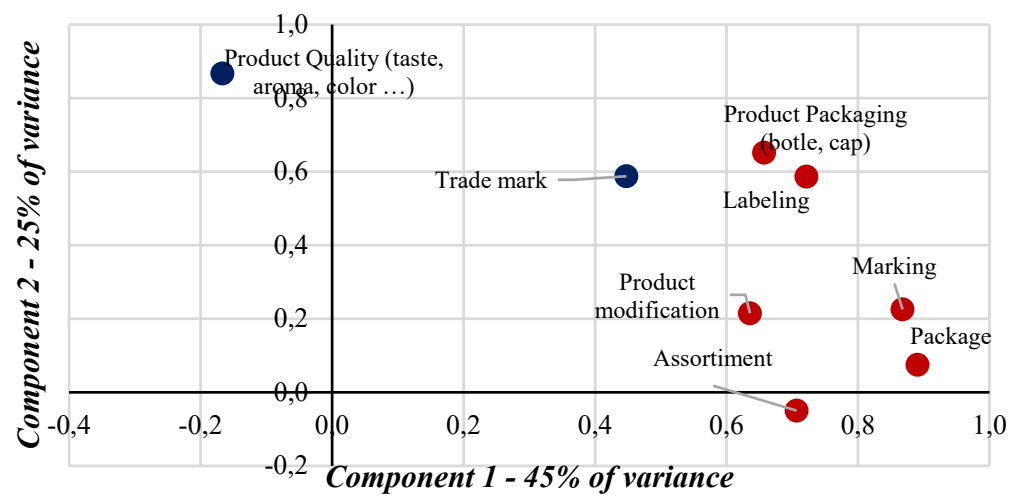

Fig. 3. Product - competitive advantages (factor analysis), Source: Own data

In one group the characteristics of the product, forming the unifying factor ,,assortment and ,product characteristics”, are highlighted, and with individual significance the „Product quality"and its ,trade mark" are displayed.

Almost all of the suggested factors related to the price are equally assessed by the wine producers as something they rely on - between $68 \%$ and $71 \%$ of them. However, as low as $40 \%$ of the respondents rely on price reduction in order to achieve competitive advantages. (Fig. 4)

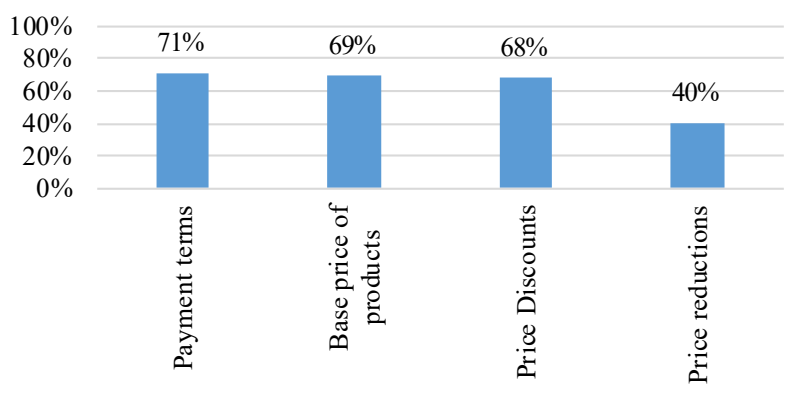

Fig. 4. Reliance of wine producers on price's factors for competitiveness, Own data

As concerns the distribution speed, rhythm and continuity of deliveries are regarded as more important $(86 \%)$ than the inventory maintenance $(75 \%)$ and the creation of own realization channels (71\%). (Fig. 5)

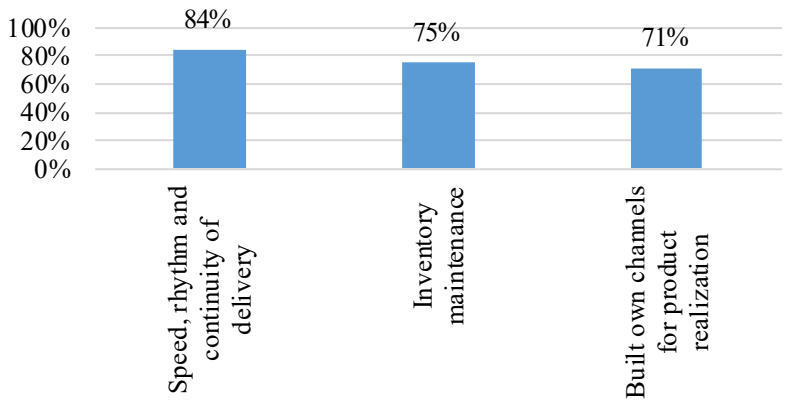

Fig. 5. Reliance of wine producers on distributions's factors for competitiveness, Source: Own data 
To promote their products the wine producers, rely mostly on participation in wine forums and exhibitions (74\%). Similarly, to the general question on the competitive advantage the advertising is one of the least utilized instruments to achieve competitiveness in the wine sector. As low as $48 \%$ of the respondents say that rely on it. (Fig. 6)

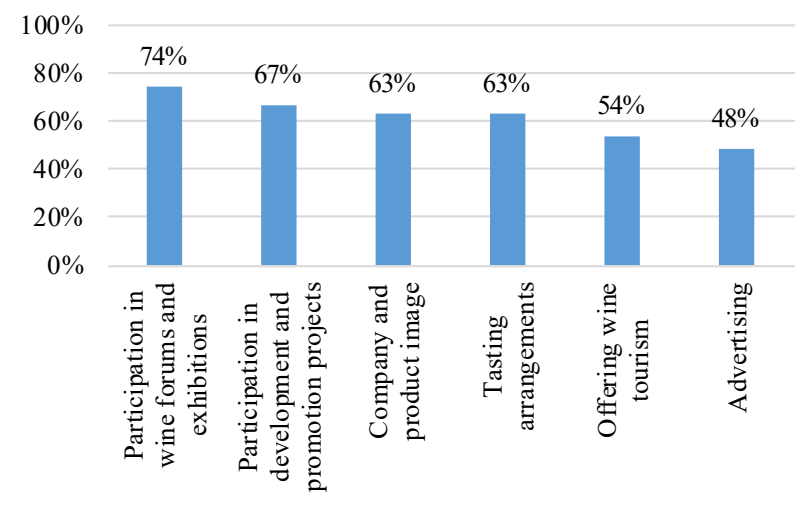

Fig. 6. Reliance of wine producers on promotion's factors for competitiveness, Source: Own data

The leading promotional activities in connection to product realization and wine tourism are deduced through a descriptive analysis (Fig. 7). Essentially, they are realized as joint or related activities between the wine producers.

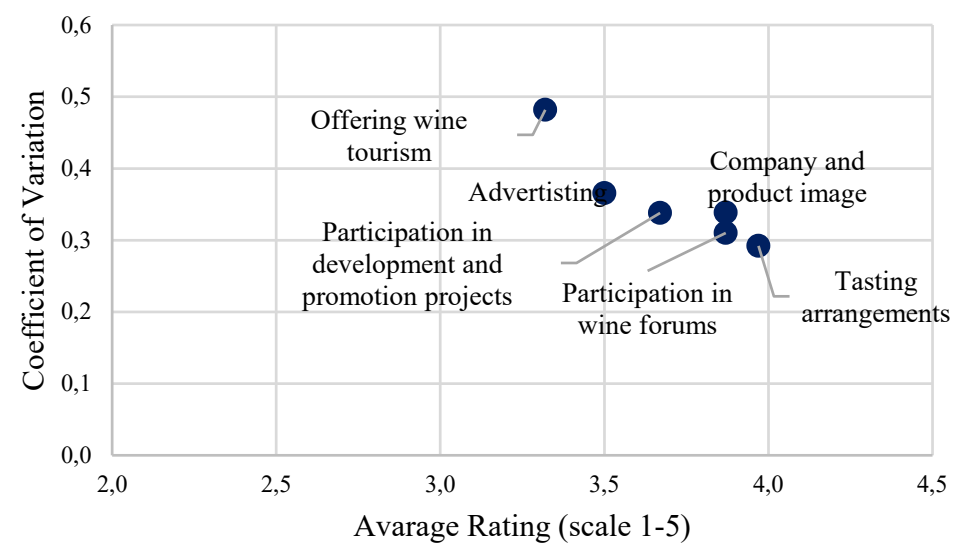

Fig. 7. Promotion - competitive advantages (descriptive analysis), Source: Own data

Among them stand out as activities of the highest importance for creating competitive advantages and increasing competitiveness, those aimed at "tasting arrangements“, „participation in wine forums“ and ,company and product image“. In essence, the first two are part of wine tourism, which in its kind, associated with visiting the wineries (,offering wine tourism"), receives the lowest degree of unanimity on the part of respondents, as a significance for competitive positioning. This is explained by the fact that most of the wine cellars in the country are still „open“ to receive visitors and offering wine tourism.

As mentioned above the management is one of the most important factors for the competitiveness of the wine sector in general and Fig. 8 displays the specific conditions of the management, which are relevant. ,production experiences and effectiveness" $(89 \%)$, ,staff qualification $(85 \%)$ and the ,technologies“ (81\%) are the most important competitive 
advantages of the management according to the wine producers. To ensure raw costs for raw materials is something that is relevant to very low extent as only $46 \%$ of the respondents regard it as important.

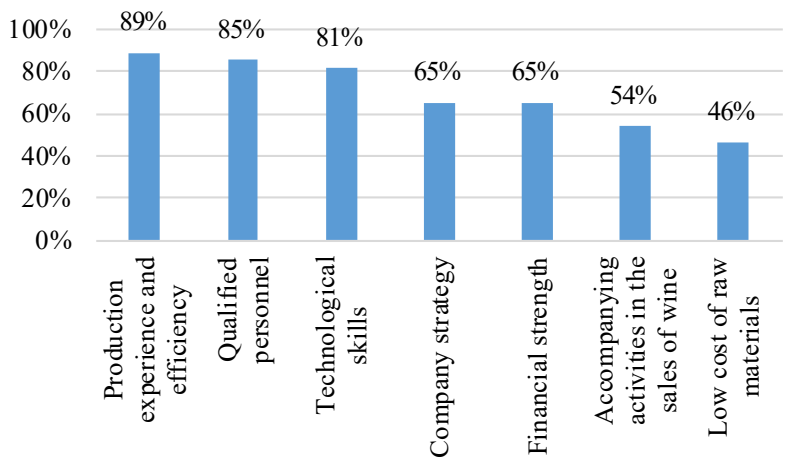

Fig. 8. Strengths and weaknesses and of the Bulgarian wine, Source: Own data

\section{Conclusions}

The competitiveness of the wine sector is important for the Bulgarian economy as a whole. Thus, it is rather significant to identify and support the competitive advantages of the sector, support and enhance them.

It is clearly defined (and proved by various researches, including the present one) that the leading strength of the Bulgarian wine production - qualitative wines from authentic local sorts (with PDO and PGI). This justifies the obligatory direction for differentiation and validation of the Bulgarian wine producers by promoting the wines of local varieties and establishing the identity of the wine regions, including through wine tourism. Based on the world's best practices established by leading wine producers, this is only possible with government support.

However, the strong competitiveness in the sector assumes strategical activities towards the popularizing of clearly distinctive products and establishing their image at the world markets. Nevertheless, the advertising doesn't seem to be among the priorities of the wine producers. Thus, steps in this direction should be made in order to enhance this area.

Indeed, the current study identified the main competitive advantages of the Bulgarian wine production some of which coincide with previous studies. However, we believe that further research is required in order to identify why the advertisement is underestimated and how to increase the activity of wine producers in this area.

\section{References}

1. EAVW, National Strategy for the Development of Vine and Wine Production in the Republic of Bulgaria 2005-2025, http://eavw.com/updocs/1413121387015401_Strategia.pdf, [Accessed: 02.2021]

2. G. Dimitrova, Competitiveness of micro- and small enterprises from wine industry (the example of Plovdiv region), (University Publishing House 'P. Hilendarski', 2019)

3. M. Angelova, M., D. Pastarmadzhieva, G. Dimitrova, P. Georgiev, Innovative Practices in Wine Industry: Opportunities for Competitiveness Enhancement in Bulgaria, in Proceedings of International conference on Creative Business for Smart and Sustainable Growth (CreBus 2019), Publisher: IEEE (2019)

4. G. Dimitrova, M. Angelova, D. Pastarmadzhieva, TJS, 17(1), 221-226 (2019) 
5. G. Dimitrova, V. Stanev, The Corporate Image As A Competitive Advantage, Union of Scientists in Bulgaria-Plovdiv, Series A. Public scientices, art and culture, 6, 79-82 (2017)

6. P. Druker, The Practice of Management, (Harper and Row Publishers Inc., N. York., 1954)

7. V. Stanev, Five contentious areas in advertisement, (University Publishing House 'P. Hilendarski', 2016)

8. A. Vasileva et al, International Competitiveness of Export-Oriented Industries in Bulgaria, (S. UNWE, 215-216, 2012)

9. D. Toteva, Impact of the Common Agricultural Policy on the development of the EU of viticulture in Bulgaria, $\mathrm{PhD}$ thesis, S. Agricultural Academy, Institute of Agricultural Economics (2015)

10. MZH, National support Programme in the Wine Sector, https://www.mzh.government.bg/media/filer_public/2019/11/20/natsionalna_programa _za_podpomagane_v_lozaro-vinarskiia_sektor_za_perioda_2019-2023_godinareviziia_1.pdf, [Accessed: 02.2021] 